\section{Adventitious Bud Formation from Callus Cultures of Japanese Persimmon}

\author{
Ryutaro Tao and Akira Sugiura \\ Laboratory of Pomology, Faculty of Agriculture, Kyoto University \\ Sakyo-ku, Kyoto 606, Japan
}

Additional index words. auxin, cytokinin, Diospyros kaki, explant origin, genotype, organogenesis, somaclonal variation

Abstract. Callus cultures were initiated in the dark from leaf primordia, stem internodes, and young leaves of adult Japanese persimmon (Diospyros kaki L.) to induce adventitious buds. A high frequency of regeneration occurred on Murashige and Skoog medium (MS) with half the normal $\mathrm{NH}_{4} \mathrm{NO}_{3}$ and $\mathrm{KNO}_{3}$ concentration $(1 / 2 \mathrm{~N})$ and containing $10 \mu \mathrm{M}$ zeatin or $1 \mu \mathrm{M} 4 \mathrm{PU}-30$ in combination with $0.1 \mu \mathrm{M}$ IAA, or MS(1/2N) medium containing 0.03 to $0.1 \mu \mathrm{M}$ IAA or 0.01 to $0.03 \mu \mathrm{M}$ NAA combined with 10 $\mu \mathrm{M}$ zeatin. No significant differences in the capacity of regeneration were observed among the calli from different explant sources. Only eight of 16 cultivars formed adventitious buds on $\mathrm{MS}(1 / 2 \mathrm{~N})$ medium containing $10 \mu \mathrm{M}$ zeatin and $0.1 \mu \mathrm{M}$ IAA, with the percentage of explants forming adventitious buds ranging from $2 \%$ to $72 \%$. Chemical names used: indole3-acetic acid (IAA); 1-naphthaleneacetic acid (NAA); $N$ phenyl-N'-(2-chloro-4-pyridyl)urea (4PU-30).

Japanese persimmon breeding programs have been hindered by a long juvenile period, large plant size, and genetic heterozygosity. Moreover, cross breeding is inhibited because only a few cultivars carry male and/ or hermaphrodite flowers.

Plants regenerated from tissue cultures have provided a new and useful source of genetic variation. Screening somaclonal variants has had a great impact on cultivar improvement where conventional breeding progress has been slow or when slight cultivar modification is desirable (DeWald and Moore, 1987). Although genetic variability may exist among plants regenerated from shoot-tip culture, most reports describe plants from such cultures as uniform (Hu and Wang, 1983). However, plants regenerated from undifferentiated tissue cultures, such as callus cultures, are reported to be highly variable (Evans et al, 1984; Skirvin, 1978). Thus, regeneration of whole plants from adventitious shoots is a prerequisite to the full use of somaclonal variation for cultivar improvement.

We previously reported adventitious bud formation and plantlet regeneration from callus cultures derived from primordial leaves of adult Japanese persimmon (Tao et al., 1988). In that study, however, we used only one cultivar, and the growth regulators examined for adventitious bud formation were limited to zeatin and IAA. Because the frequency of adventitious bud formation depends on various factors (Flick et al., 1983), understanding them is important to achieve a high level of regeneration. In the present

Received for publication 28 May 1991. Accepted for publication 28 Aug. 1991. The cost of publishing this paper was defrayed in part by the payment of page charges. Under postal regulations, this paper therefore must be hereby marked $a d$ vertisement solely to indicate this fact. study, the influence of growth regulators, explant origin, and genotype on the regenerative capacity of callus cultures of Japanese persimmon was investigated.

Dormant 1-year-old shoots of 16 cultivars of Japanese persimmon trees growing in the orchard of Kyoto Univ. were collected in December and stored in plastic bags at $0 \mathrm{C}$ for several months. Axillary buds were removed and surface-sterilized for $15 \mathrm{~min}$ in a sodium hypochlorite solution of $1 \%(\mathrm{w} / \mathrm{v})$ containing $0.1 \%$ (v/v) Tween 20 , followed by four sterile-water washes. Primordial leaves
${ }^{\mathrm{z} M e a n}$ number of adventitious buds per responsive explant.

${ }^{2}$ Mean number of adventitious buds per responsive explant. were excised under a binocular microscope, and the four leaf primordia were each placed in a separate test tube $(23 \times 150 \mathrm{~mm})$ containing $20 \mathrm{ml}$ of medium. Internode sections (10 mm long) and young leaves just after unfolding were also excised from actively growing shoots of 'Jiro', 30 days after budbreak. These explants were disinfested as described for dormant buds and placed on medium. The culture medium used was modified Murashige and Skoog's salts plus vitamins (Murashige and Skoog, 1962) with half the normal $\mathrm{NH}_{4} \mathrm{NO}_{3}$ and $\mathrm{KNO}_{3}$ concentration [MS(1/2N)] (Sugiura et al., 1986) and supplemented with $10 \mu \mathrm{M}$ zeatin and $1 \mu \mathrm{M}$ IAA. The callus cultures were maintained by subculturing to the same medium at $\approx 40-$ day intervals. After several subcultures, they were subdivided and used for further experiments.

Growth regulators (Expt. 1). Callus cultures derived from primordial leaves of 'Jiro' were used to determine the effect of diverse cytokinins and auxins on adventitious bud formation. The calli were subdivided and cultured on $\mathrm{MS}(1 / 2 \mathrm{~N})$ medium supplemented with either 4PU-30, N-phenylN'1,2,3-thidiazol-5-yl urea (TDZ), zeatin, 6-benzylaminopurine (BA), or 2-isopentenylaminopurine $(2 \mathrm{iP})$ in combination with 0.1 $\mu \mathrm{M}$ IAA (Table 1 ), or on $\mathrm{MS}(1 / 2 \mathrm{~N})$ medium containing 2,4-dichlorophenoxyacetic acid (2,4-D), IAA, indole3-butyric acid (IBA), or NAA combined with $10 \mu \mathrm{M}$ zeatin (Table 2). There were 25 explants per treatment, and the experiment was conducted once.

Explant origin (Expt. 2). Callus cultures of 'Jiro' derived from leaf primordia, stem internodes, and young leaves were used to determine the effect of explant origin on adventitious bud formation. The calli, after three

Table 1. Effect of various types of cytokinin at several concentrations on adventitious bud formation in callus from leaf primordia of Japanese persimmon 'Jiro'. All media contained $0.1 \mu \mathrm{M}$ IAA.

\begin{tabular}{|c|c|c|c|c|c|}
\hline \multirow{3}{*}{$\begin{array}{l}\text { Concn } \\
(\mu \mathrm{M})\end{array}$} & \multicolumn{5}{|c|}{ Percent explants forming adventitious buds } \\
\hline & \multicolumn{5}{|c|}{ Cytokinin } \\
\hline & 4PU-30 & TDZ & Zeatin & $\mathrm{BA}$ & $2 \mathrm{iP}$ \\
\hline 0 & 0 & ... & --. & -.- & --- \\
\hline 0.1 & 0 & 0 & --. & --. & -- \\
\hline 0.3 & $4(1.0)^{z}$ & 0 & --. & --. & --. \\
\hline 1 & $48(3.6)$ & $4(1.0)$ & 0 & --. & --. \\
\hline 3 & $28(2.7)$ & & $8(1.3)$ & 0 & 0 \\
\hline 10 & -.. & -.. & $44(2.6)$ & $4(1.0)$ & 0 \\
\hline 30 & -.. & --. & $20(2.6)$ & 0 & $4(1.0)$ \\
\hline 100 & -- & --. & --. & 0 & 0 \\
\hline
\end{tabular}

Table 2. Effect of various types of auxin at several concentrations on adventitious bud formation in callus from leaf primordia of Japanese persimmon 'Jiro'. All media contained $10 \mu \mathrm{M}$ zeatin.

\begin{tabular}{llccc}
\hline \hline & \multicolumn{4}{c}{ Percent explants forming adventitious buds } \\
\cline { 2 - 5 } $\begin{array}{l}\text { Concn } \\
(\mu \mathrm{M})\end{array}$ & \multicolumn{4}{c}{ Auxin } \\
\cline { 2 - 5 } & $2,4-\mathrm{D}$ & IAA & IBA & NAA \\
\hline 0 & $8(2.0)^{\mathrm{z}}$ & $24(3.8)$ & $12(1.0)$ & $36(2.8)$ \\
0.01 & $16(2.3)$ & $40(3.4)$ & $12(3.0)$ & $32(2.0)$ \\
0.03 & 0 & $44(2.6)$ & $12(2.0)$ & $20(3.0)$ \\
0.1 & 0 & $28(2.3)$ & $16(1.3)$ & 0 \\
0.3 & 0 & $20(2.0)$ & $4(1.0)$ & 0 \\
1 & 0 & & &
\end{tabular}




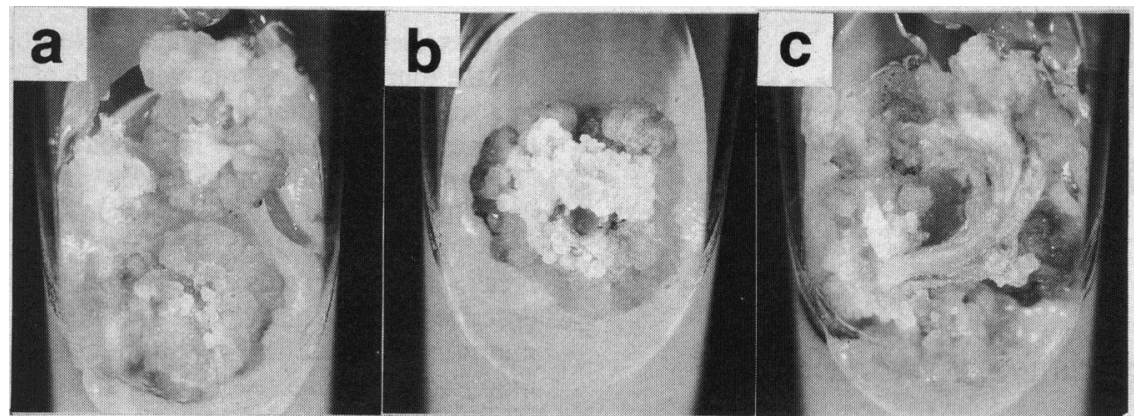

Fig. 1. Callus from leaf primordium (a), stem internode (b), and young leaf(c) of Japanese persimmon 'Jiro' after 40 days of culture.

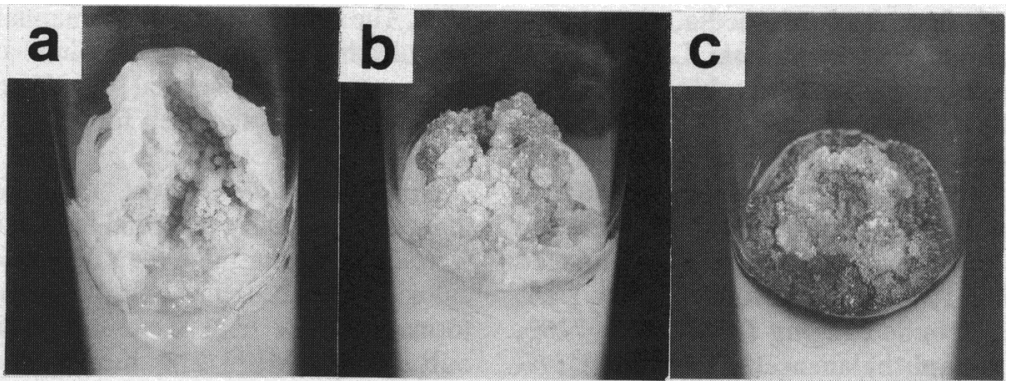

Fig. 2. Calli from leaf primordia of Japanese persimmon 'Saijo' (a), 'Kurogaki' (b), and 'Nagara' (c) after three subcultures.

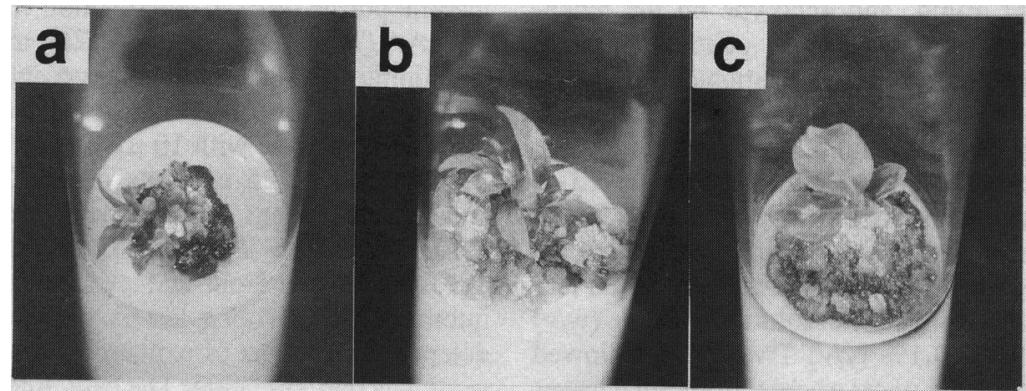

Fig. 3. Adventitious shoots on callus derived from leaf primordia of Japanese persimmon 'Chokenji' (a), 'Jiro' (b), and 'Meotogaki' (c).

Table 3. Effect of genotype on adventitious bud formation in callus derived from leaf primordia of Japanese persimmon.

\begin{tabular}{llc}
\hline \hline Genotype & $\begin{array}{c}\text { Callus } \\
\text { color }\end{array}$ & $\begin{array}{c}\text { Percent } \\
\text { explants forming } \\
\text { adventitious buds }\end{array}$ \\
\hline Aizu Mishirazu & $\mathrm{Gr}^{\mathbf{z}}$ & $0 \mathrm{a}^{\mathbf{y}}$ \\
Chokenji & $\mathrm{Gr}$ & $13 \mathrm{a}(3.0)^{\mathbf{x}}$ \\
E Gosho & $\mathrm{Br}$ & $2 \mathrm{a}(2.0)$ \\
Fuyu & $\mathrm{Br}$ & $0 \mathrm{a}$ \\
Hana Gosho & $\mathrm{Br}$ & $0 \mathrm{a}$ \\
Hiratanenashi & $\mathrm{Gr}$ & $0 \mathrm{a}$ \\
Jiro & $\mathrm{Yw}$ & $42 \mathrm{~b}(2.8)$ \\
Kurogaki & $\mathrm{Br}$ & $3 \mathrm{a}(1.0)$ \\
Meotogaki & $\mathrm{Gr}$ & $43 \mathrm{~b}(1.4)$ \\
Mushiroda Gosho & $\mathrm{Yw}$ & $2 \mathrm{a}(1.0)$ \\
Nagara & $\mathrm{Br}$ & $0 \mathrm{a}$ \\
Saijo & $\mathrm{Yw}$ & $72 \mathrm{c}(3.4)$ \\
Suruga & $\mathrm{Yw}$ & $7 \mathrm{a}(1.5)$ \\
Tamopan & $\mathrm{Br}$ & $0 \mathrm{a}$ \\
Yoshino & $\mathrm{Gr}$ & $0 \mathrm{a}$ \\
Zenjimaru & $\mathrm{Br}$ & $0 \mathrm{a}$ \\
\hline
\end{tabular}

${ }^{2}$ Callus color during subcultures; $\mathrm{Br}=$ brown, $\mathrm{Gr}=$ gray, $\mathrm{Yw}=$ yellowish-white .

'Mean separation in a column by Duncan's multiple range test, $P=0.01$.

${ }^{x}$ Mean number of adventitious buds per responsive explant. culture. In Expts. 2 and 3, the percentage of adventitious bud formation was analyzed using analysis of variance (ANOVA) after arcsin transformation. Means were separated by Duncan's multiple range test.

Growth regulators. Hard globular calli formed at the cut surfaces of leaf primordia of 'Jiro' $\approx 10$ days after the start of culture, and the original explants were completely covered with callus after 40 days of culture (Fig. la). We reported similar results earlier (Tao et al., 1988). Calli, after three to five subcultures, were used for this experiment because preliminary experiments showed that the regeneration capacity of the calli was almost constant during this period of subculture. In comparisons of various kinds of cytokinins at several concentrations in combination with $0.1 \mu \mathrm{M}$ IAA, $10 \mu \mathrm{M}$ zeatin, and $1 \mu \mathrm{M} 4 \mathrm{PU}-30$ yielded the best results (Table 1). The other cytokinins were much less effective, and only one explant formed an adventitious bud each with TDZ, BA, and $2 \mathrm{iP}$ at 1,10 , and $30 \mu \mathrm{M}$, respectively. TDZ and several substituted pyridyl phenylurea compounds have been demonstrated to have strong cytokinin-like activity and stimulate callus growth and shoot formation at unusually low concentrations (Fellman et al., 1987; Mok et al., 1987). In this experiment, 4PU-30 had similar activity at a concentration 10 times less than the optimum zeatin concentration for adventitious bud formation. TDZ, however, was ineffective for adventitious bud formation in callus of Japanese persimmon. Of the auxins tested in the presence of $10 \mu \mathrm{M}$ zeatin. IAA and NAA were most effective, with 0.03 to 0.1 and 0.01 to $0.03 \mu \mathrm{M}$, respectively, yielding the best results (Table 2). Compared to IAA or NAA, 2,4-D and IBA were less effective for adventitious bud formation. Concentrations of 2,4-D higher than $0.01 \mu \mathrm{M}$ stimulated excessive growth of callus and no regeneration occurred. 2,4-D enhanced callus growth at lower levels than did other auxins.

Explant origin. As with leaf primordia, hard globular calli were produced from the cut surfaces of stem internodes (Fig. lb) and young leaves of 'Jiro' (Fig. lc). No differences in the appearance and color were observed among the calli from different explant origins after three subcultures. When they were cultured on $\mathrm{MS}(1 / 2 \mathrm{~N})$ medium supplemented with $10 \mu \mathrm{M}$ zeatin and $0.1 \mu \mathrm{M}$ IAA, which seemed to be the optimal regeneration medium in Expt. 1, 43\%, 50\%, and 35\% of the calli from leaf primordia, stem internodes, and young leaves, respectively, formed adventitious buds. No significant differences $(P=0.01)$ were found in the percentages of adventitious bud formation. In contrast to our results, explant origin has been shown to affect regeneration in-other species (Flick et al., 1983).

Genotype. Leaf primordia of all 16 cultivars formed calli after 40 days of culture. There was a wide range of variation in callus appearance and color (Table 3), from yellowish-white with 'Saijo' to brown with 'Nagara'. The differences were retained even after three subcultures (Fig. 2). When they 
were transferred to the regeneration medium, the calli of eight cultivars produced adventitious buds (Fig. 3 and Table 3). The percentages of explants forming adventitious buds ranged from $72 \%$ for 'Saijo' to $2 \%$ for 'Mushiroda Gosho'. The eight other cultivars produced no adventitious buds. However, it is not clear whether the growth regulator requirements for these cultivars differed or if there were differences in their regeneration capacity.

In this study, the type and level of growth regulators in the medium and the genotype appeared to affect regeneration from callus cultures of Japanese persimmon. In contrast, the explant source used for callus initiation was not important. Our earlier (Tao et al., 1988) and this work on regeneration have been based primarily on one of the most economically important cultivars, 'Jiro'. However, half of the cultivars tested in this experiment did not form adventitious buds on their callus under optimal conditions for 'Jiro'. It might be necessary to establish an optimal regeneration medium for a given cultivar.

\section{Literature Cited}

Dewald, S.G. and G.A. Moore. 1987. Somaclonal variation as a tool for the improvement of perennial fruit crops. Fruit Var. J. 41:54-57.

Evans, D.A., W.R. Sharp, and H.P.M.-Filho. 1984. Somaclonal and gametoclonal variation. Amer. J. Bot. 71:759-774.

Fellman, C.D., P.E. Read, and M.A. Hosier. 1987. Effects of thidiazuron and CPPU on meristem formation and shoot proliferation. HortScience 22:1197-1200.

Flick, C.E., D.A. Evans, and W.R. Sharp. 1983. Organogenesis, p. 13-81. In: D.A. Evans, W.R. Sharp, P.V. Ammirato, and Y. Yamada (eds.). Handbook of plant cell culture. vol. 1. Macmillan, New York.

Hu, C.Y. and P.J. Wang. 1983. Meristem, shoot tip, and bud culture, p. 177-227. In: D.A. Evans, W.R. Sharp, P.V. Ammirato, and Y. Yamada (eds.). Handbook of plant cell culture. vol. 1. Macmillan, New York.

Mok, M.C., D.W.S. Mok, J.E. Turner, and C.V. Mujer. 1987. Biological and biochemical effects of cytokinin-active phenylurea derivatives in tissue culture systems. HortScience 22:11941197.

Murashige, T. and F. Skoog. 1962. A revised medium for rapid growth and bioassays with tobacco tissue culture. Physiol. Plant. 15:473497.

Skirvin, R.M. 1978. Natural and induced variation in tissue culture. Euphytica 27:241-266.

Sugiura, A., R. Tao, H. Murayama, and T. Tomana. 1986. In vitro propagation of Japanese persimmon. HortScience 21:1205-1207.

Tao, R., H. Murayama, K. Moriguchi, and A. Sugiura. 1988. Plant regeneration from callus cultures derived from primordial leaves of adult Japanese persimmon. HortScience 23:10551056. 